\title{
Frequent FGFR1 hotspot alterations in driver-unknown low-grade glioma and mixed neuronal-glial tumors
}

\author{
Sophie Engelhardt ${ }^{1} \cdot$ Felix Behling $^{2,3} \cdot$ Rudi Beschorner $^{1,3} \cdot$ Franziska Eckert $^{3,4,5} \cdot$ Patricia Kohlhof $^{6}$. \\ Marcos Tatagiba $^{2,3} \cdot$ Ghazaleh Tabatabai $^{3,5,7,8} \cdot$ Martin U. Schuhmann ${ }^{2,3,9} \cdot$ Martin Ebinger $^{10} \cdot$ Jens Schittenhelm $^{1,3}$ (1)
}

Received: 23 September 2021 / Accepted: 25 December 2021 / Published online: 11 January 2022

(c) The Author(s) 2022

\begin{abstract}
Purpose Low-grade gliomas (LGG) and mixed neuronal-glial tumors (MNGT) show frequent MAPK pathway alterations. Oncogenic fibroblast growth factor receptor 1 (FGFR1) tyrosinase kinase domain has been reported in brain tumors of various histologies. We sought to determine the frequency of FGFR1 hotspot mutations N546 and K656 in driver-unknown LGG/ MNGT and examined FGFR1 immunohistochemistry as a potential tool to detect those alterations.

Methods We analyzed 476 LGG/MNGT tumors for KIAA-1549-BRAF fusion, IDH1/2, TERT promotor, NF1, H3F3A and the remaining cases for FGFR1 mutation frequency and correlated FGFR1 immunohistochemistry in 106 cases.

Results 368 of 476 LGG/MNGT tumors contained non-FGFR1 alterations. We identified 9 FGFR 1 p.N546K and 4 FGFR1 p.K656E mutations among the 108 remaining driver-unknown samples. Five tumors were classified as dysembryoplastic neuroepithelial tumor (DNT), 4 as pilocytic astrocytoma (PA) and 3 as rosette-forming glioneuronal tumor (RGNT). FGFR1 mutations were associated with oligodendroglia-like cells, but not with age or tumor location. FGFR1 immunohistochemical expression was observed in 92 cases. FGFR1 immunoreactivity score was higher in PA and DNT compared to diffuse astrocytoma, but no correlation between FGFR1 mutation in tumors and FGFR1 expression level was observed. Conclusion FGFR1 hotspot mutations are the fifth most prevailing alteration in LGG/MNGT. Performing FGFR1 sequencing analysis in driver-unknown low-grade brain tumors could yield up to 12\% FGFR1 N546/K656 mutant cases.
\end{abstract}

Keywords FGFR1 · Pyrosequencing · Low-grade glioma $\cdot$ Mixed neuronal glial tumor · Immunohistochemistry

Jens Schittenhelm

jens.schittenhelm@med.uni-tuebingen.de

1 Department of Neuropathology, Institute of Pathology and Neuropathology, University Hospital of Tuebingen, Eberhard Karls University of Tuebingen, Calwerstr. 3, 72076 Tuebingen, Germany

2 Department of Neurosurgery, University Hospital of Tuebingen, Eberhard Karls University Tuebingen, 72076 Tuebingen, Germany

3 Center for Neuro-Oncology, Comprehensive Cancer Center Tuebingen-Stuttgart, University Hospital of Tuebingen, Eberhard Karls University of Tuebingen, Tuebingen, Germany

4 Department of Radiation Oncology, University Hospital Tuebingen, Hoppe-Seyler-Str. 3, 72076 Tuebingen, Germany

5 German Consortium for Translational Cancer Research (DKTK), DKFZ Partner Site Tuebingen, Tuebingen, Germany
6 Institute for Pathology, Katharinenhospital Stuttgart, Stuttgart, Germany

7 Department of Neurology and Interdisciplinary Neurooncology, University Hospital Tübingen, Hertie-Institute for Clinical Brain Research, Eberhard Karls University Tübingen, 72076 Tuebingen, Germany

8 Center for Personalized Medicine, Eberhard Karls University of Tuebingen, Tuebingen, Germany

9 Division of Pediatric Neurosurgery, Department of Neurosurgery, University Hospital of Tuebingen, Eberhard Karls University of Tuebingen, Tuebingen, Germany

10 Department Pediatric Hematology/Oncology, Children's University Hospital, Eberhard Karls University of Tuebingen, Tuebingen, Germany 


\section{Introduction}

Low-grade gliomas (LGG) and the WHO category of mixed neuronal-glial tumors (MNGT) encompass a broad spectrum of mostly pediatric tumors with usually indolent clinical behavior or long-term epilepsy-associated sequelae (Surrey et al. 2019). Excellent outcome can be achieved through gross total resection. However, cases with incompletely resected tumors may experience a chronic, relapsing course (de Blank et al. 2019). Some recurring tumors have poor response rates with chemotherapy and risks of long-term toxicity of irradiation must be carefully weighed in children (Ater et al. 2012). The designation LGG is not consistently used in pediatric and adult neuro-oncology. LGG in 'adult-type' diffuse gliomas is used for isocitrate dehydrogenase (IDH) 1 and 2 mutant tumors or IDH-wildtype gliomas exhibiting molecular features of high-grade gliomas and usually progressing to glioblastoma histology (Komori 2021). In contrast, 'pediatric-type' LGG include many circumscribed gliomas and tumor progression is rarely reported. Distinct morphologically defined entities of LGG and MNGT include pilocytic astrocytoma (PA), ganglioglioma (GG), dysembryoplastic neuroepithelial tumor (DNT), polymorphous low-grade neuroepithelial tumor of the young (PLNTY), papillary glioneuronal tumor (PGNT) and rosette-forming glioneuronal tumor (RGNT). Recent advances in genomic discoveries allow for a molecular approach for LGG and MNGT stratification and new entities of so called 'pediatric-type' diffuse gliomas based on recurrent alterations have been proposed (Ellison et al. 2019). Diffusely growing gliomas in children and adolescents usually show genetic aberrations within the mitogen-activated protein kinase (MAPK) pathway and are characterized by the absence of isocitrate dehydrogenase (IDH) 1 and 2 hotspot and H3 histone, family 3A (H3F3A) mutations (Lazow et al. 2020). The most frequent single driver alterations in these tumors are a v-Raf murine sarcoma viral oncogene homolog B (BRAF) V600E mutation, a fibroblast growth factor receptor (FGFR) 1 alteration, or a v-Myb avian myeloblastosis viral oncogene homolog (MYB) or MYBL1 rearrangement which are all associated with a rather favourable outcome (Qaddoumi et al. 2016; Yang et al. 2018). These driving genetic alterations are usually conserved at tumor recurrence (Lazow et al. 2020). Some MAPK alterations overlap with distinct histological subtypes. For example, the BRAF V600E mutation is frequently seen in GG and pleomorphic xanthoastrocytoma (PXA) but is also sometimes reported in PA and diencephalic diffuse glioma (Ho et al. 2015). Similarly, isomorphic diffuse gliomas frequently show MYBL1 (54\%) or MYB (23\%) rearrangements but these alterations are also seen in diffuse astrocytomas
(DA) (Ellison et al. 2019; Zhang et al. 2013). Other alterations are highly diagnostic for a specific tumor entity. The majority of PA exhibit characteristic KIAA1549-BRAF fusions (Collins et al. 2015) and PGNT show a unique methylation profile and highly diagnostic PRKCA fusions (Hou et al. 2019). In contrast, some alterations encompass a broad spectrum of LGG and MNGT tumors and show age-related distribution patterns (Ryall et al. 2020). Especially, FGFR alterations are observed in several tumor entities in up to $7 \%$ of neoplasms (Helsten et al. 2016). In brain tumors, FGFR 1 alterations are not restricted to tumor grade or a specific age group (Bale 2020).

Four receptors (FGFR1 to FGFR4) and 18 ligands (fibroblast growth factors) have been discovered in humans and have an important role in cell growth, differentiation and neovascularization (Bale 2020; Katoh and Nakagama 2014). Upon ligand binding, FGFR dimerizes and phosphorylates intracellular kinase domains (for example Tyr724 and Tyr760 in FGFR3) thus activating several important druggable pathways including Ras/Raf/MEK and PI3K-Akt (Katoh and Nakagama 2014; Nelson et al. 2018). FGFR1-tyrosinase kinase domain duplications are more prevalent in extracerebellar PA and DNT (Jones et al. 2013; Rivera et al. 2016). In contrast, FGFR1-TACC1 fusion is a distinctive alteration of extraventricular neurocytoma in addition to a small number of other rare FGFR1 and FGFR3 fusions (Sievers et al. 2018). Additional frequent reported alterations are the oncogenic FGFR1 tyrosinase kinase domain hotspot mutations N546 and K656 (Lew et al. 2009). These mutations have been reported in midline and extracerebellar PA (Jones et al. 2013), in posterior fossa PA with widespread oligodendroglial features (Sievers et al. 2020), in DNT (Surrey et al. 2019; Rivera et al. 2016) and in RGNT (Lucas et al. 2020). Furthermore, they are also observed in diffuse midline gliomas in addition to H3 K27M mutations (Schüller et al. 2021). A recent study associated FGFR1 mutations in low-grade glioma with increased risk for intracranial bleeding (Ishi et al. 2020). In experimental murine NF1 models, a co-occurring FGFR 1 hotspot mutation confers an additional growth advantage in LGG (Fisher et al. 2021). These hotspot mutations are of great interest, because FGFR alterations can be targeted by inhibitors including the multi tyrosine kinase inhibitors ponatinib, lucitanib and nintedanib (Porta et al. 2017). Some of these FGFR inhibitors are currently under investigation in phase I/II targeted trials for advanced solid tumors (Voss et al. 2019; Touat et al. 2015).

Taken together, the reported FGFR1 N546 and K656 hotspot mutations show a significant overlap in LGG and MNGT entities, are driven by altered MAPK signalling and represent potential diagnostic as well as predictive markers for clinical trial inclusions and eventually clinical management. Open questions addressed in this study include (i) the 
actual frequency of FGFR1 N546 and K656 hotspot mutations in an unselected collection of low-grade brain tumors independent of their histological designation and (ii) the potential screening role of FGFR1 immunohistochemistry to identify FGFR1 alterations in such tumors.

\section{Material and methods}

\section{Biological specimen}

The formalin-fixated, paraffin-embedded samples were obtained from patients undergoing surgery for brain tumors between 2000 and 2018 at the University Hospital Tübingen. The study was authorized by the respective ethics board (number 708/2017BO2). Histological diagnosis, molecular typing and grading for each tumor sample were performed according to the current WHO classification of CNS tumors (Louis et al. 2016). Tumor location, gender, survival, tumor status (primary/progression), NF1 status and patient age were retrieved from the clinical records.

681 tumors were listed after initial search from the pathology records for LGG and MNGT diagnosis and cases were reviewed. Eleven samples were excluded, because the remaining archived tumor tissue was too small for immunohistochemistry or molecular analysis. 476 tumors remained after checking for consent of scientific use of samples (Fig. 1A). Based on available data from clinical records or additionally performed molecular analysis as outlined below, the following 368 cases with one or more non-FGFR 1 alteration were identified: Confirmed neurofibromatosis type 1 in 35 cases, IDH1 mutation in 221 cases, IDH2 mutation in nine cases, $1 p / 19 q$ codeletion in four cases without and in 112 cases with IDH1/2 mutation, TERT promotor hotspot mutation in 24 cases without and in 21 cases with IDH1/2 mutation, H3F3A K27M mutation in two cases and KIAA1549-BRAF fusion in 73 cases. Table 1 summarizes the frequency of mentioned alterations for initial tumor diagnosis. Because FGFR1 alterations usually do not occur in the context of these mutations, the subsequent FGFR1 analysis was restricted to the remaining cases without known driver-mutation (Picca et al. 2018). The final FGFR1 sequencing and staining study cohort consisted of 108 samples (45 female and 63 male, mean age 22.8 range $0.6-71$ years, Fig. 1A). Epidemiologic details of FGFR 1 cohort are shown in Table 2. In 94 cases, the primary tumor and in 20 cases the recurrent tumor was used for analysis because either the primary tumor was not available or not sufficiently DNA could be extracted.

\section{Molecular diagnostics}

IDH1/2, H3F3A, ATRX, BRAF and LOH1p/19q analysis in the Tübingen cohort was performed as described
A

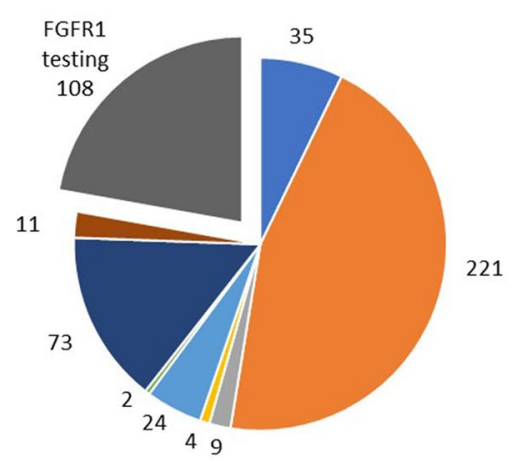

- NF1 = IOH1 = IDH2 = LOH1p19q = TERT \& H3F3A K27M - KLAA-BRAF = Insufficent \& Testing cohort

B
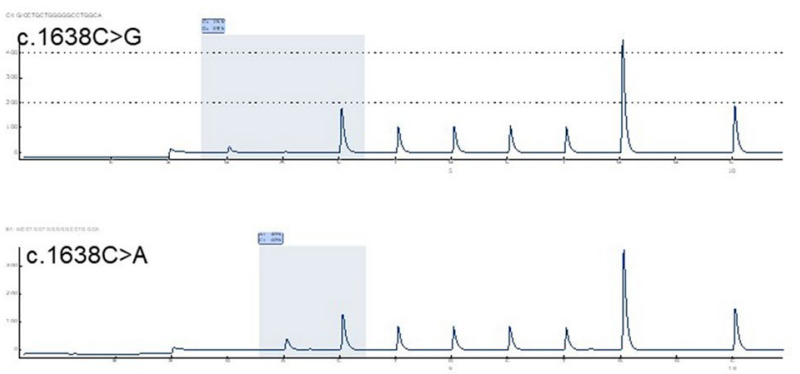

C

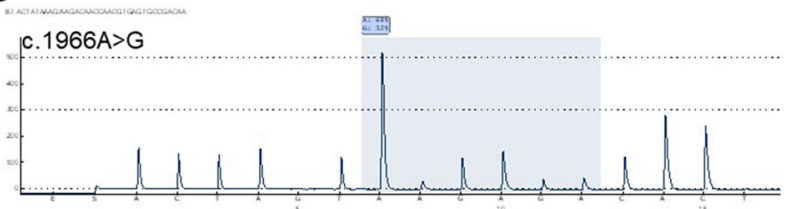

Fig. 1 A Distribution of Non-FGFR1 mutations across 476 tumors. Sample numbers are provided on top for each slice. 108 samples without known mutation were selected for FGFR1 testing. B Representative pyrograms for FGFR1 N546K mutation (five cases with c. $1638 \mathrm{C}>\mathrm{A}$ and four with c. $1638 \mathrm{C}>\mathrm{G}$ ). $\mathrm{C}$ Representative pyrogram for FGFR1 K656E mutation (four cases with c.1966A > G)

previously (Ebrahimi et al. 2016). Briefly, the IDH R132H and H3F3A K27M mutational status was first determined by immunohistochemistry. All grade II/III tumors lacking the $\mathrm{R} 132 \mathrm{H}$ mutation and grade IV samples aged below 55 years were further examined by direct pyrosequencing of the relevant exons for IDH1 and two hotspot mutations. Cases with ATRX loss and IDH1/2 wildtype status or cases with midline location were sequenced for H3F3A K27 and G34 mutations. Diffuse low-grade gliomas without IDH1/2 mutation were sequenced for BRAF and TERT promotor mutations (Koelsche et al. 2013). Loss of heterozygosity (LOH 1p/19q) was examined in IDH1/2 mutant tumors with 


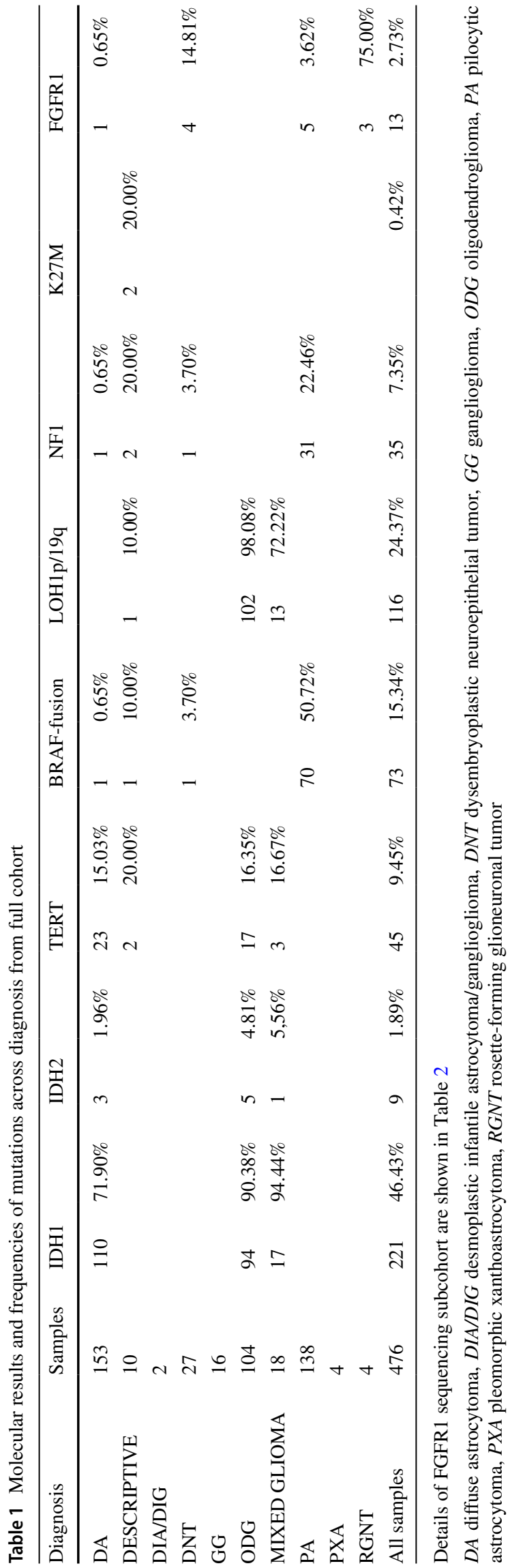

ATRX retention using 5 tetranucleotide markers for each chromosomal region. Allele signal intensity of each tumor sample was always compared with the corresponding allele band of the blood control sample of each corresponding patient. BRAF fusion analysis was performed using fusiontranscript-specific PCR after RNA was extracted from FFPE samples using the RNeasy FFPE Kit (Qiagen) (Gierke et al. 2016). Methylation classification analysis on the EPIC platform was retrieved from cases enrolled in the MNP2.0, or PTT trials in five cases (Illumina, Carlsbad, California, USA) and evaluated as previously described (Capper et al. 2018), Tumors were classified with an established brain tumor classifier V11b4 (www.molecularneuropathology. org). Classifier scores with a probability greater 0.9 were taken as indicative for the respective methylation class.

\section{FGFR1 pyrosequencing}

Using a BlackPREP FFPE kit (Analytik Jena, Germany), DNA was extracted from the microdissected tumor tissue according to the manufacturer's instructions. Tissue was selected from regions on paraffin blocks that presented sufficient (> 50\%) tumor content in microscopy. The region around FGFR1 c.546 was amplified with the following primers: FGFR1 c.546 -forward, 5'-CGGACGCAACAG AGAAAGACTT-3' and FGFR1 c.546 -reverse biotinylated primer, 5'-[BIO]CCCAGATCCCGAGATAACACA-3'. For c. 656 we used FGFR1 c.656 -forward, 5'-ACGGGACAT TCACCACATC-3' and FGFR1 c.656 -reverse biotinylated primer, 5'-[BIO]CACCCCACTCCTTGCTTC-3'. In all cases, the estimated sizes of the amplification products detected corresponded to the predicted sizes.

Pyrosequencing was performed on the Pyromark Q24 system according to the manufacturer's instructions (Qiagen, Hilden, Germany). For pyrosequencing we used starting primer FGFR1 (c.546 5'-AAGCATAAGAATATCATC AA-3' c.656 5'- CATTCACCACATCGACT-3') with dispensation orders'GACTGCTGGC' for c.546 and 'ACTAGT AAGAGACACT' for c.656. Pyrograms were analyzed with the PyroMarkQ24 software (Version 2.0.7 Build 3) and a level of $5 \%$ for relative light units for variant detection was applied. FGFR1 positive cases were confirmed by repeated pyrosequencing.

\section{FGFR1 immunohistochemistry}

Staining was performed on the Benchmark IHC/ISH (Ventana Medical Systems) after several optimization rounds for tissue pretreatment, antigen demasking and antibody dilution. FGFR 1 protein expression was detected by immunohistochemistry using a polyclonal antibody raised against phospho-FGFR1 (Tyr653, Tyr654) of human origin (RRID:AB_1500112,\#44-1140G, Thermo-Fisher Waltham, 
Table 2 Epidemiological data of samples used for comparative FGFR1 pyrosequencing and immunohistochemistry

\begin{tabular}{|c|c|c|c|c|c|c|}
\hline Diagnosis & $N$ cases & Mean age (yr.) & Min age (yr.) & Max age (yr.) & Gender F/M & $\begin{array}{l}\text { Primary/ } \\
\text { Recur- } \\
\text { rent }\end{array}$ \\
\hline DA & 16 & 35.3 & 4 & 71 & $6 / 10$ & $15 / 1$ \\
\hline DIA/DIG & 2 & 0.7 & 0.6 & 0.75 & $1 / 1$ & $2 / 0$ \\
\hline DNT & 26 & 15.2 & 1 & 43 & $13 / 13$ & $19 / 7$ \\
\hline GG & 15 & 27.9 & 3 & 59 & $5 / 10$ & $14 / 1$ \\
\hline ODG & 2 & 4.5 & 4 & 5 & $0 / 2$ & $2 / 0$ \\
\hline PA & 37 & 21.4 & 1.5 & 60 & $14 / 23$ & $30 / 7$ \\
\hline PXA & 4 & 20.5 & 6 & 51 & $3 / 1$ & $3 / 1$ \\
\hline RGNT & 4 & 37 & 11 & 58 & $1 / 3$ & $3 / 1$ \\
\hline DESCRIPTIVE & 2 & 24.5 & 3 & 46 & $2 / 0$ & $0 / 2$ \\
\hline
\end{tabular}

$D A$ diffuse astrocytoma, $D I A / D I G$ desmoplastic infantile astrocytoma/ganglioglioma, $D N T$ dysembryoplastic neuroepithelial tumor, $G G$ ganglioglioma, $O D G$ oligodendroglioma, $P A$ pilocytic astrocytoma, $P X A$ pleomorphic xanthoastrocytoma, $R G N T$ rosette-forming glioneuronal tumor. $F$ female, $M$ male, $y r$ year
MA, USA). Samples of breast cancer tissue served as positive control. Staining conditions were as follows: FGFR1: OptiView CC1 pretreatment for $32 \mathrm{~min}, 1: 100$ dilution, incubated at room temperature for $32 \mathrm{~min}$. All slides were then counterstained with hematoxylin for 2 min. FGFR 1 staining intensities were scored as published previously as 0 (no staining), 1 (weak staining), 2 (moderate staining) and 3 (strong staining). For exemplary images see Supplemental Fig. 1. In addition, positive staining in tumors was quantified as follows: 1 (up to $24 \%$ tumor cells positive), 2 (25-50\% tumor cells positive, 3 (51-75\% tumor cells positive) and 4 (more than $75 \%$ tumor cells positive). Staining intensities were multiplied with staining quantification into a combined immunoreactivity score (IRS) ranging from 0 to 12 .

\section{TCGA dataset and statistical analysis}

Sequencing profiles of patients with LGG of the central nervous system were retrieved from The Cancer Genome Atlas (TCGA) database (https://portal.gdc.cancer.gov/ TCGA-LGG). The clinical datasets (mean age 42.9 years, range 14-87 years) consisted of 460 females and 570 males After exclusion of 416 anaplastic tumors, the final set consisted of 128 astrocytomas, 156 oligodendrogliomas and 262 mixed gliomas. Samples were screened for IDH1/2, H3F3A, NF1, BRAF and FGFR1 mutations. Sample-matching TERT promotor mutations and LOH $1 \mathrm{p} / 19 \mathrm{q}$ status were derived from tabulated data provided by (Ceccarelli et al. 2016). Quantitative and statistical analyses were performed using JMP 14.2.0 (SAS Institute, Cary, NJ, USA). For correlation analyses, we performed unpaired, two-tailed Student's $t$-test and the Fisher's exact test to identify possible significant associations or differences between two pairs. Univariate analyses of the different variables were obtained with $95 \%$ confidence intervals (CIs). A $p$ value $<0.05$ was considered as significant.

\section{Results}

\section{FGFR1 pyrosequencing identifies FGFR1 hotspot mutations in $12 \%$ of the LGG/MNGT subcohort of driver unknown cases}

108 samples without entity-defining molecular alterations were analyzed for FGFR1 hotspot mutations in pyrosequencing (Fig. 1A) and in 105 cases the signal passed quality checks. We detected 13 (12\%) FGFR1 hotspot mutations. A p.N546K mutation was observed in 9/105 tumors (8\%, five cases with c. $1638 \mathrm{C}>\mathrm{A}$ and four with c.1638C $>\mathrm{G}$, exemplary pyrograms shown in Fig. 1B). Among the p.N546K mutated cases, three tumors were diagnosed as DNT, four tumors as PA, one tumor as RGNT and the remaining tumor only had a descriptive diagnosis of low-grade neuroepithelial tumor.

A FGFR1 p.K656E mutation was observed in 4/103 tumors $(3 \%$, c. $1966 \mathrm{~A}>\mathrm{G}$; Fig. 1C). Two p.K656E mutated tumors were diagnosed as RGNT, one as PA and one as DNT. Taken together, one of the two FGFR1 hotspot mutations was present in 5/37 (13\%) PA, in 4/26 (15\%) DNT and in $3 / 4(75 \%)$ RGNT. None of the tumors histologically diagnosed as DA $(n=16)$, GG $(n=15)$, PXA $(n=4)$ or DIA/DIG $(n=2)$ exhibited a FGFR1 p.N546K or p.K656E mutation.

\section{Clinicopathological overview of FGFR1 mutant cases}

All FGFR 1 mutant cases were reviewed histologically. Common histological features included low cellularity with round nuclei and frequent oligodendroglia-like tumor cells, loosened fibrillary matrix with focal myxoid appearance and low to absent mitotic activity. Vascular proliferations, hemosiderin deposits and calcifications were present in two cases each. Perivascular inflammation was noted in one case. The initial histological diagnosis was confirmed in 11 cases 
reviewed. One case had a descriptive diagnosis of low-grade neuroepithelial tumor. Detailed histological review of this case showed oligodendroglial-like cells within a loosened myxoid matrix, suggestive of DNT despite absence of floating neurons (Fig. 2). The last case diagnosed initially as DNT showed overlapping features of PA/DNT in review. External reference pathology review (second opinion) in this case also discussed PA/DNT and provided a descriptive diagnosis of low-grade neuroepithelial tumor. Radiological appearance and clinical features also favored DNT in this case and consolidating the initial diagnosis.

Seven of the FGFR1 mutated cases were male, six were female. Six cases were pediatric (3-16 years) and seven cases were adults (23-58 years). FGFR1 mutation was not associated with a distinct tumor location. Seven mutated cases were located supratentorial, six cases were located in the cerebellum. Complete resection could be achieved in seven and subtotal resection in three cases. In the limited follow-up period (2-13 months), three tumors showed progression (one subtotal, one partial resection and one case with biopsy only). In one case, tissue of the recurring tumor was available and the identical FGFR1 hotspot mutation was detected. Presenting symptoms of the tumors included epileptic seizures $(n=4)$, headache $(n=5)$, vertigo $(n=2)$, visual disturbances $(n=3)$ and facial nerve palsy $(n=2)$. There was no significant age difference between the 13 FGFR 1 mutant cases combined (mean age 25.8 years) compared to 92 cases without FGFR1 hotspot mutation (mean age 22.6 years, $p=0.564$ ). Patients with a FGFR1 p.N546K mutation were slightly but not significantly younger (mean age 19.6 years) and the FGFR1 p.K656E mutant tumors were significantly older at diagnosis (mean age 39.7 years) compared to wildtype cases. In the histological subanalysis,

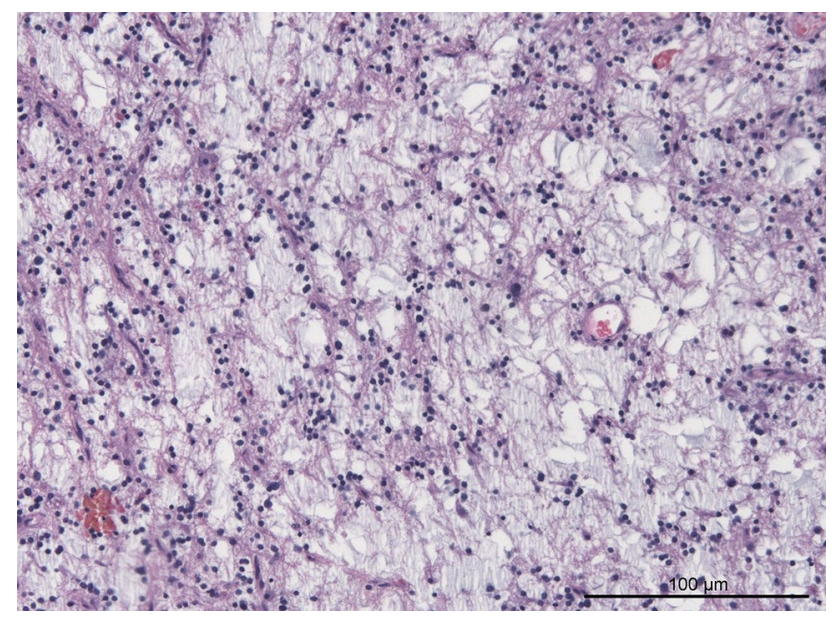

Fig. $2 \mathrm{H} \& \mathrm{E}$ stain of a case with descriptive diagnosis of low-grade neuroepithelial tumor exhibiting a c.1638C $>$ A p.N546K hotspot mutation suggesting DNT as appropriate diagnosis. Reference review pathology also suggested DNT as most likely diagnosis in this case
FGFR1 mutated RGNT cases were older (mean age 45.6 years) than the FGFR1 wildtype RGNT case (11yrs), while PA (mean 22.1 vs. 19.6 years) and DNT (mean 14.7 vs. 13.7 years) FGFR1 mutant cases were seen at similar age as FGFR1 wildtype tumors.

\section{Positive FGFR1 immunohistochemistry does not identify tumors with FGFR1 p.N546 or p.K656 hotspot mutation}

Sufficient tissue for FGFR1 staining was available in 106 samples. Expression of FGFR1 was observed in the cytoplasm and membrane of tumor cells and staining intensity was homogenous throughout the tumor tissue. FGFR1 immunohistochemistry staining examples are shown in Supplementary Fig. 1. Absence of staining (score 0) was observed in 16 cases. Weak FGFR 1 expression (intensity score 1) was seen in 42 cases (39\%), moderate staining intensity (score 2) was present in 30 cases (28\%) and strong expression was seen in 18 cases $(17 \%)$.

Number of positively stained cells varied across divergent tumors. A staining distribution score 1 (less than 25\% positive tumor cells) was observed in 3 cases, distribution score 2 in 14 cases, distribution score 3 in 22 cases and distribution score 4 (more than $75 \%$ tumor cells positive) in 51 cases.

Combining staining intensity and number of positive cells into an immunoreactive score showed low IR scores (1-4) in 41 cases, intermediate IR scores (5-8) in 36 cases and high IR scores (9-12) in 13 cases.

The FGFR1 IR scores were independent of patient age $(p=0.8725)$ and gender $(p=0.554)$. Primary tumors had nonsignificantly lower FGFR1 IR scores (mean 4.8) compared to tumor recurrences (mean 5.7, $p=0.326$ ). FGFR1 IR scores were significantly higher in WHO grade I tumors (mean 5.4, $p=0.0053$ ) compared to WHO grade II tumors (mean 2.8). For FGFR1 immunohistochemistry details across histological diagnoses, see Table 3. Interestingly, FGFR1 IR score was significantly higher in PA (mean 6.4, $p=0.0002$ ), PXA (mean 7.8, $p=0.0101$ ) and DNT (mean $4.8, p=0.0255$ ) compared to DA (mean 2.3).

FGFR1 IR scores in p.N546K or p.K656E mutated tumors were higher (mean 5.8) than in FGFR1 wild-type tumors (mean 4.9. $p=0.0370$ ), but results were also not significant in further subgroup analysis after separation for WHO grade or tumor recurrences.

\section{TCGA dataset analysis}

Among 614 sample datasets with LGG histology record, we identified 253 cases with IDH1 and 14 cases with IDH2 mutation. TERT promotor mutations were found in 154, LOH $1 p / 19 q$ codeletion in $81, N F 1$ alterations in 10 and a 
Table 3 FGFR1 immunohistochemistry

\begin{tabular}{llll}
\hline Diagnosis & $N$ & Mean IRS & SD IRS \\
\hline DA & 16 & 2.3 & 2.52 \\
DNT & 26 & 4.8 & 3.70 \\
PXA & 3 & 7.8 & 0.28 \\
GG & 15 & 4.5 & 2.89 \\
PA & 37 & 6.4 & 3.52 \\
RGNT & 4 & 5.6 & 3.35 \\
Other & 7 & 3.5 & 4.17 \\
\hline
\end{tabular}

Mean and standard deviation (SD) of immunreactive score (IRS) by histological diagnosis

$D A$ diffuse astrocytoma, $D I A / D I G$ desmoplastic infantile astrocytoma/ganglioglioma, $D N T$ dysembryoplastic neuroepithelial tumor, $G G$ ganglioglioma, $O D G$ oligodendroglioma, $P A$ pilocytic astrocytoma, $P X A$ pleomorphic xanthoastrocytoma, $R G N T$ rosette-forming glioneuronal tumor

BRAF V600E mutation in two cases. One case each exhibited a KIAA1549-BRAF fusion, a H3F3A K27M mutation and one missense FGFR1 N577K mutation. The FGFR1 mutant case was a 34-year-old male with diagnosis of oligodendroglioma grade II. No follow-up data were available in this case. A cross-check with the COSMIC database (URL: https://cancer.sanger.ac.uk/cosmic/mutation/overview?id= 125179833, accessed on 28.10.2021) shows that the FGFR1 N577K mutation has been reported previously in five highgrade gliomas and two RGNT.

\section{Discussion}

A significant subset of low-grade gliomas and mixed neuronal-glial tumors demonstrate ambiguous or overlapping morphological features and diagnostic accuracy of brain tumors can be improved through combining histological and molecular data (Lucas et al. 2020). With the present study we tried to determine the frequency of potentially actionable FGFR1 hotspot mutant tumors in a histological diagnosis-independent subcohort of LGG/MNGT without other known driver mutations. Among 476 tumors with molecular data available, we identified 13 activating FGFR1 p.N546 or p.K656 mutant cases, while 368 tumors exhibited nonFGFR1 alterations. This indicates an overall frequency of 2.7\% FGFR1 hotspot mutations in unselected LGG/MNGT cohorts. The most common non-FGFR1 alterations were IDH1/2 mutations (234 cases), KIAA1549-BRAF fusion (73 cases), 24 TERT C228/C250-mutated gliomas and 35 cases with NF1. In our cohort, FGFR1 hotspot mutations are the fifth most occurring genetic alteration in LGG/ MNGT tumors. A systematic FGFR1 analysis of these samples after exclusion of these four more frequent mutations would result in 12\% FGFR1 N546/K656 mutant cases. The
FGFR1 mutations were observed only in tumors diagnosed as pilocytic astrocytoma, dysembryoblastic neuroepithelial tumors and rosette-forming glioneuronal tumor. Therefore, further restricting the FGFR1 sequencing analysis to nondiffusely growing gliomas/MNGT tumors would yield $15 \%$ FGFR1 N546/K656 mutant cases after exclusion of cases with BRAF fusion, IDH1/2, NF1 or TERT mutation. We did not find FGFR1 hotspot mutations in our DA or PXA. As seen from the additional TCGA dataset analysis, FGFR1 alterations in DA are rare. In this context, it is noteworthy, that while PA, DNT and RGNT share frequent FGFR1 hotspot alterations they represent epigenetically distinct tumor entities with separate methylation clusters (Capper et al. 2018). In accordance with our data, Qaddoumi et al. reported FGFR1 hotspot mutations only in DNT and diffuse oligodendroglial tumors, while DA instead contained one FGFR1 fusion and two FGFR1 TKD duplications (Qaddoumi et al. 2016). A study analyzing the molecular profile of adult brainstem gliomas reported a surprisingly high FGFR 1 mutation frequency in $18 \%$ of patients (13/73 cases) (Picca et al. 2018). These mutations were also reported in thalamic and cerebellar tumors in both H3F3A K27M mutated and K27 wild-type tumors. The vast majority of these cases had a high-grade histology, whereas our cohort was intentionally restricted to LGG and MNGT tumors. Both low-grade tumors with H3F3A K27M mutation underwent panel-sequencing and co-occurring FGFR1 mutations could be excluded. Methylation analysis in these cases clearly clustered them together with K27M-mutant pontine gliomas suggesting histological underdiagnosis due to limited sample size. Another integrated molecular analysis of 70 low-grade glioma cases with NF1 tumors revealed 3 FGFR1 hotspot mutation. Such tumors were classified as non-pilocytic astrocytoma based on DNA methylation analysis (Fisher et al. 2021). Except for a single DA case, all NF1 tumors in our initial selection cohort consisted of classical PA, in which no FGFR1 mutations are expected. Three quarters of our RGNT samples were FGFR1 mutated in accordance with a previous publication identifying FGFR1 hotspot mutations in 10/10 RGNTs (Lucas et al. 2020). A previous study reported p.N546K $(n=22)$ or p.K656E $(n=8)$ alterations in all 30 RGNT and additional PIK3CA mutations in $63 \%$ and NF1 mutations in $23 \%$ of these tumors (Sievers et al. 2019). As expected, the majority (44\%) of PA exhibited KIAA1549BRAF fusions, followed by $12 \%$ NF1 mutant and $3 \%$ FGFR1 mutant samples. Again this data is in agreement with the suggested frequency of 5\% FGFR1 mutations in pilocytic astrocytoma (Collins et al. 2015). While the detection of an FGFR1 alteration in a LGG/MNGT tumor of uncertain subtype may not aid in differential diagnosis between PA, DNT and RGNT, it may help to further narrow the differential diagnosis and exclude certain tumor entities, such as DA and PXA. A study reported on five LGG cases with DNA 
methylation profiles that did not align with any reference methylation classes but had FGFR1-alterations. In these cases, oligodendroglial-like cells without well-defined patterned nodules, floating neurons, neurocytic rosettes, piloid processes, Rosenthal fibers, or other specific histologic findings, were described (Lucas et al. 2020). Because in two cases a FGFR1 alteration in combination with PIK3CA or PIK3R1 mutation was present, the authors questioned whether such samples may represent a yet-to-be defined tumor class of RGNT outside of the stereotypic location in the fourth ventricle. Furthermore, the FGFR1 hotspots may provide a rationale for targeted FGFR1 treatment (Porta et al. 2017).

As a large center with expertise in pediatric neurooncology the cases referred to us have an inherent selection bias for challenging neurosurgery cases which in turn may impact frequency of FGFR1 alterations. Further limitations of our study include the retrospective nature and archived sample retrieval, differences in the clinical indications for biopsy and restrictions on the amount and type of material available for molecular characterization and restriction of samples to driver unknown LGG/MNGT. Because methylation array tumor clustering is not feasible in such a large cohort, our approach to select cases by histology diagnosis, does not completely exclude cases with potential FGFR1-TACC1 fusions and FGFR1-TKD tandem duplication (Qaddoumi et al. 2016). As this study proposes additional molecular hotspot FGFR1 testing for a subset of driver unknown LGGs, we intentionally restricted our cohort to previously non-informative cases after removing mutually exclusive entity-defining mutations (Picca et al. 2018). However in rare instances, three secondary FGFR1 hotspot mutations have been reported among 364 IDH-mutant gliomas and such cases may have been missed by our methodology (Ahrendsen et al. 2021).

Taken together, our analysis indicates that FGFR1 hotspot mutations are a common event in non-diffusely growing gliomas, especially in PA, DNT and RGNT cohorts, and not associated with a distinct histological pattern further suggesting that MAPK-altered tumors in pediatric and adult samples encompass a broad spectrum of tumors. Performing FGFR1 sequencing analysis routinely in non-diffusely growing driver-unknown low-grade brain tumors could yield up to $15 \%$ FGFR1 N546/K656 mutant cases.

Supplementary Information The online version contains supplementary material available at https://doi.org/10.1007/s00432-021-03906-x.

Acknowledgements We like to thank Nadin Krischker and Natalia Karpekin for assistance with pyrosequencing.

Author contributions All authors made substantial contributions to the study, i.e., conception, design, sample acquisition, clinical data acquisition, data analysis, data interpretation and coordination of experiments and collaborations. JS and SE designed and coordinated the study, evaluated, analyzed and interpreted the molecular results. JS wrote the first draft of the manuscript, SE performed molecular analysis, created figures and data table. RB provided histological review. FB, MS, GT, FE, MT, ME provided clinical data and/or specimen. All authors read, modified the manuscript and approved the final version.

Funding Open Access funding enabled and organized by Projekt DEAL. None.

\section{Declarations}

Conflict of interest GT served on Advisory Boards of BMS, MSD and AbbVie; received research and/or travel grants from Roche Diagnostics, Novocure and Medac, received speakers` fees from Medac, Novocure. FB received funding for industry sponsored workshops from Medac and Arbor Pharmaceuticals. SE, RB, FE, ME and JS have no conflict of interest to declare.

Open Access This article is licensed under a Creative Commons Attribution 4.0 International License, which permits use, sharing, adaptation, distribution and reproduction in any medium or format, as long as you give appropriate credit to the original author(s) and the source, provide a link to the Creative Commons licence, and indicate if changes were made. The images or other third party material in this article are included in the article's Creative Commons licence, unless indicated otherwise in a credit line to the material. If material is not included in the article's Creative Commons licence and your intended use is not permitted by statutory regulation or exceeds the permitted use, you will need to obtain permission directly from the copyright holder. To view a copy of this licence, visit http://creativecommons.org/licenses/by/4.0/.

\section{References}

Ahrendsen JT, Torre M, Meredith DM, Hornick JL, Reardon DA, Wen PY, Yeo KK, Malinowski S, Ligon KL, Ramkissoon S, Alexandrescu S (2021) IDH-mutant gliomas with additional class-defining molecular events. Mod Pathol 34:1236-1244

Ater JL, Zhou T, Holmes E, Mazewski CM, Booth TN, Freyer DR, Lazarus KH, Packer RJ, Prados M, Sposto R, Vezina G, Wisoff JH, Pollack IF (2012) Randomized study of two chemotherapy regimens for treatment of low-grade glioma in young children: a report from the Children's Oncology Group. J Clin Oncol 30:2641-2647

Bale TA (2020) FGFR- gene family alterations in low-grade neuroepithelial tumors. Acta Neuropathol Commun 8:21

Capper D, Jones DTW, Sill M, Hovestadt V, Schrimpf D, Sturm D, Koelsche C, Sahm F, Chavez L, Reuss DE, Kratz A, Wefers AK, Huang K, Pajtler KW, Schweizer L, Stichel D, Olar A, Engel NW, Lindenberg K, Harter PN, Braczynski AK, Plate KH, Dohmen H, Garvalov BK, Coras R, Holsken A, Hewer E, Bewerunge-Hudler M, Schick M, Fischer R, Beschorner R, Schittenhelm J, Staszewski O, Wani K, Varlet P, Pages M, Temming P, Lohmann D, Selt F, Witt H, Milde T, Witt O, Aronica E, Giangaspero F, Rushing E, Scheurlen W, Geisenberger C, Rodriguez FJ, Becker A, Preusser M, Haberler C, Bjerkvig R, Cryan J, Farrell M, Deckert M, Hench J, Frank S, Serrano J, Kannan K, Tsirigos A, Bruck W, Hofer S, Brehmer S, Seiz-Rosenhagen M, Hanggi D, Hans V, Rozsnoki S, Hansford JR, Kohlhof P, Kristensen BW, Lechner M, Lopes B, Mawrin C, Ketter R, Kulozik A, Khatib Z, Heppner F, Koch A, Jouvet A, Keohane C, Muhleisen H, Mueller W, Pohl U, Prinz M, Benner A, Zapatka M, Gottardo NG, Driever PH, 
Kramm CM, Muller HL, Rutkowski S, von Hoff K, Fruhwald MC, Gnekow A, Fleischhack G, Tippelt S, Calaminus G, Monoranu CM, Perry A, Jones C, Jacques TS, Radlwimmer B, Gessi M, Pietsch T, Schramm J, Schackert G, Westphal M, Reifenberger G, Wesseling P, Weller M, Collins VP, Blumcke I, Bendszus M, Debus J, Huang A, Jabado N, Northcott PA, Paulus W, Gajjar A, Robinson GW, Taylor MD, Jaunmuktane Z, Ryzhova M, Platten M, Unterberg A, Wick W, Karajannis MA, Mittelbronn M, Acker T, Hartmann C, Aldape K, Schuller U, Buslei R, Lichter P, Kool M, Herold-Mende C, Ellison DW, Hasselblatt M, Snuderl M, Brandner S, Korshunov A, von Deimling A, Pfister SM (2018) DNA methylation-based classification of central nervous system tumours. Nature 555:469-474

Ceccarelli M, Barthel FP, Malta TM, Sabedot TS, Salama SR, Murray BA, Morozova O, Newton Y, Radenbaugh A, Pagnotta SM, Anjum S, Wang J, Manyam G, Zoppoli P, Ling S, Rao AA, Grifford M, Cherniack AD, Zhang H, Poisson L, Carlotti CG Jr, Tirapelli DP, Rao A, Mikkelsen T, Lau CC, Yung WK, Rabadan R, Huse J, Brat DJ, Lehman NL, Barnholtz-Sloan JS, Zheng S, Hess K, Rao G, Meyerson M, Beroukhim R, Cooper L, Akbani R, Wrensch M, Haussler D, Aldape KD, Laird PW, Gutmann DH, Noushmehr H, Iavarone A, Verhaak RG (2016) Molecular profiling reveals biologically discrete subsets and pathways of progression in diffuse glioma. Cell 164:550-563

Collins VP, Jones DT, Giannini C (2015) Pilocytic astrocytoma: pathology, molecular mechanisms and markers. Acta Neuropathol 129:775-788

de Blank P, Bandopadhayay P, Haas-Kogan D, Fouladi M, Fangusaro J (2019) Management of pediatric low-grade glioma. Curr Opin Pediatr 31:21-27

Ebrahimi A, Skardelly M, Bonzheim I, Ott I, Muhleisen H, Eckert F, Tabatabai G, Schittenhelm J (2016) ATRX immunostaining predicts IDH and H3F3A status in gliomas. Acta Neuropathol Commun 4:60

Ellison DW, Hawkins C, Jones DTW, Onar-Thomas A, Pfister SM, Reifenberger G, Louis DN (2019) cIMPACT-NOW update 4: diffuse gliomas characterized by MYB, MYBL1, or FGFR1 alterations or BRAF(V600E) mutation. Acta Neuropathol 137:683-687

Fisher MJ, Jones DTW, Li Y, Guo X, Sonawane PS, Waanders AJ, Phillips JJ, Weiss WA, Resnick AC, Gosline S, Banerjee J, Guinney J, Gnekow A, Kandels D, Foreman NK, Korshunov A, Ryzhova M, Massimi L, Gururangan S, Kieran MW, Wang Z, Fouladi M, Sato M, Øra I, Holm S, Markham SJ, Beck P, Jäger N, Wittmann A, Sommerkamp AC, Sahm F, Pfister SM, Gutmann DH (2021) Integrated molecular and clinical analysis of low-grade gliomas in children with neurofibromatosis type 1 (NF1). Acta Neuropathol 141:605-617

Gierke M, Sperveslage J, Schwab D, Beschorner R, Ebinger M, Schuhmann MU, Schittenhelm J (2016) Analysis of IDH1-R132 mutation, BRAF V600 mutation and KIAA1549-BRAF fusion transcript status in central nervous system tumors supports pediatric tumor classification. J Cancer Res Clin Oncol 142:89-100

Helsten T, Elkin S, Arthur E, Tomson BN, Carter J, Kurzrock R (2016) The FGFR landscape in cancer: analysis of 4,853 tumors by nextgeneration sequencing. Clin Cancer Res 22:259-267

Ho CY, Mobley BC, Gordish-Dressman H, VandenBussche CJ, Mason GE, Bornhorst M, Esbenshade AJ, Tehrani M, Orr BA, LaFrance DR, Devaney JM, Meltzer BW, Hofherr SE, Burger PC, Packer RJ, Rodriguez FJ (2015) A clinicopathologic study of diencephalic pediatric low-grade gliomas with BRAF V600 mutation. Acta Neuropathol 130:575-585

Hou Y, Pinheiro J, Sahm F, Reuss DE, Schrimpf D, Stichel D, Casalini B, Koelsche C, Sievers P, Wefers AK, Reinhardt A, Ebrahimi A, Fernández-Klett F, Pusch S, Meier J, Schweizer L, Paulus W, Prinz M, Hartmann C, Plate KH, Reifenberger G, Pietsch T, Varlet P, Pagès M, Schüller U, Scheie D, de Stricker K, Frank S, Hench
J, Pollo B, Brandner S, Unterberg A, Pfister SM, Jones DTW, Korshunov A, Wick W, Capper D, Blümcke I, von Deimling A, Bertero L (2019) Papillary glioneuronal tumor (PGNT) exhibits a characteristic methylation profile and fusions involving PRKCA. Acta Neuropathol 137:837-846

Ishi Y, Yamaguchi S, Hatanaka KC, Okamoto M, Motegi H, Kobayashi $\mathrm{H}$, Terasaka S, Houkin K (2020) Association of the FGFR1 mutation with spontaneous hemorrhage in low-grade gliomas in pediatric and young adult patients. J Neurosurg 134:733-741

Jones DT, Hutter B, Jäger N, Korshunov A, Kool M, Warnatz HJ, Zichner T, Lambert SR, Ryzhova M, Quang DA, Fontebasso AM, Stütz AM, Hutter S, Zuckermann M, Sturm D, Gronych J, Lasitschka B, Schmidt S, Seker-Cin H, Witt H, Sultan M, Ralser M, Northcott PA, Hovestadt V, Bender S, Pfaff E, Stark S, Faury D, Schwartzentruber J, Majewski J, Weber UD, Zapatka M, Raeder B, Schlesner M, Worth CL, Bartholomae CC, von Kalle C, Imbusch CD, Radomski S, Lawerenz C, van Sluis P, Koster J, Volckmann R, Versteeg R, Lehrach H, Monoranu C, Winkler B, Unterberg A, Herold-Mende C, Milde T, Kulozik AE, Ebinger M, Schuhmann MU, Cho YJ, Pomeroy SL, von Deimling A, Witt O, Taylor MD, Wolf S, Karajannis MA, Eberhart CG, Scheurlen W, Hasselblatt M, Ligon KL, Kieran MW, Korbel JO, Yaspo ML, Brors B, Felsberg J, Reifenberger G, Collins VP, Jabado N, Eils R, Lichter P, Pfister SM (2013) Recurrent somatic alterations of FGFR1 and NTRK2 in pilocytic astrocytoma. Nat Genet 45:927-932

Katoh M, Nakagama H (2014) FGF receptors: cancer biology and therapeutics. Med Res Rev 34:280-300

Koelsche C, Sahm F, Capper D, Reuss D, Sturm D, Jones DT, Kool M, Northcott PA, Wiestler B, Böhmer K, Meyer J, Mawrin C, Hartmann C, Mittelbronn M, Platten M, Brokinkel B, Seiz M, Herold-Mende C, Unterberg A, Schittenhelm J, Weller M, Pfister S, Wick W, Korshunov A, von Deimling A (2013) Distribution of TERT promoter mutations in pediatric and adult tumors of the nervous system. Acta Neuropathol 126:907-915

Komori T (2021) Grading of adult diffuse gliomas according to the 2021 WHO Classification of Tumors of the Central Nervous System. Lab Invest https://doi.org/10.1038/s41374-021-00667-6. Online ahead of print

Lazow MA, Hoffman L, Schafer A, Osorio DS, Boué DR, Rush S, Wright E, Lane A, DeWire-Schottmiller MD, Smolarek T, Sipple J, Taggert H, Reuss J, Salloum R, Hummel TR, de Blank P, PillaySmiley N, Sutton ME, Asher A, Stevenson CB, Drissi R, Finlay JL, Fouladi M, Fuller C (2020) Characterizing temporal genomic heterogeneity in pediatric low-grade gliomas. Acta Neuropathol Commun 8:182

Lew ED, Furdui CM, Anderson KS, Schlessinger J (2009) 'The precise sequence of FGF receptor autophosphorylation is kinetically driven and is disrupted by oncogenic mutations. Sci Signal 2:ra6

Louis DN, Perry A, Reifenberger G, von Deimling A, FigarellaBranger D, Cavenee WK, Ohgaki H, Wiestler OD, Kleihues P, Ellison DW (2016) The 2016 World Health Organization Classification of Tumors of the Central Nervous System: a summary. Acta Neuropathol 131:803-820

Lucas CG, Gupta R, Doo P, Lee JC, Cadwell CR, Ramani B, Hofmann JW, Sloan EA, Kleinschmidt-DeMasters BK, Lee HS, Wood MD, Grafe M, Born D, Vogel H, Salamat S, Puccetti D, Scharnhorst D, Samuel D, Cooney T, Cham E, Jin LW, Khatib Z, Maher O, Chamyan G, Brathwaite C, Bannykh S, Mueller S, Kline CN, Banerjee A, Reddy A, Taylor JW, Clarke JL, Oberheim Bush NA, Butowski N, Gupta N, Auguste KI, Sun PP, Roland JL, Raffel C, Aghi MK, Theodosopoulos P, Chang E, Hervey-Jumper S, Phillips JJ, Pekmezci M, Bollen AW, Tihan T, Chang S, Berger MS, Perry A, Solomon DA (2020) Comprehensive analysis of diverse low-grade neuroepithelial tumors with FGFR1 alterations reveals 
a distinct molecular signature of rosette-forming glioneuronal tumor. Acta Neuropathol Commun 8:151

Nelson KN, Meyer AN, Wang CG, Donoghue DJ (2018) Oncogenic driver FGFR3-TACC3 is dependent on membrane trafficking and ERK signaling. Oncotarget 9:34306-34319

Picca A, Berzero G, Bielle F, Touat M, Savatovsky J, Polivka M, Trisolini E, Meunier S, Schmitt Y, Idbaih A, Hoang-Xuan K, Delattre JY, Mokhtari K, Di Stefano AL, Sanson M (2018) FGFR1 actionable mutations, molecular specificities, and outcome of adult midline gliomas. Neurology 90:e2086-e2094

Porta R, Borea R, Coelho A, Khan S, Araújo A, Reclusa P, Franchina T, Van Der Steen N, Van Dam P, Ferri J, Sirera R, Naing A, Hong D, Rolfo C (2017) FGFR a promising druggable target in cancer: Molecular biology and new drugs. Crit Rev Oncol Hematol 113:256-267

Qaddoumi I, Orisme W, Wen Ji, Santiago T, Gupta K, Dalton JD, Tang Bo, Haupfear K, Punchihewa C, Easton J, Mulder H, Boggs K, Shao Y, Rusch M, Becksfort J, Gupta P, Wang S, Lee RP, Daniel Brat V, Collins P, Dahiya S, George D, Konomos W, Kurian KM, McFadden K, Serafini LN, Nickols H, Perry A, Shurtleff S, Gajjar A, Boop FA, Klimo PD, Mardis ER, Wilson RK, Baker SJ, Zhang J, Gang Wu, Downing JR, Tatevossian RG, Ellison DW (2016) Genetic alterations in uncommon low-grade neuroepithelial tumors: BRAF, FGFR1, and MYB mutations occur at high frequency and align with morphology. Acta Neuropathol 131:833-845

Rivera B, Gayden T, Carrot-Zhang J, Nadaf J, Boshari T, Faury D, Zeinieh M, Blanc R, Burk DL, Fahiminiya S, Bareke E, Schüller U, Monoranu CM, Sträter R, Kerl K, Niederstadt T, Kurlemann G, Ellezam B, Michalak Z, Thom M, Lockhart PJ, Leventer RJ, Ohm M, MacGregor D, Jones D, Karamchandani J, Greenwood CM, Berghuis AM, Bens S, Siebert R, Zakrzewska M, Liberski PP, Zakrzewski K, Sisodiya SM, Paulus W, Albrecht S, Hasselblatt M, Jabado N, Foulkes WD, Majewski J (2016) Germline and somatic FGFR1 abnormalities in dysembryoplastic neuroepithelial tumors. Acta Neuropathol 131:847-863

Ryall S, Zapotocky M, Fukuoka K, Nobre L, Guerreiro Stucklin A, Bennett J, Siddaway R, Li C, Pajovic S, Arnoldo A, Kowalski PE, Johnson M, Sheth J, Lassaletta A, Tatevossian RG, Orisme W, Qaddoumi I, Surrey LF, Li MM, Waanders AJ, Gilheeney S, Rosenblum M, Bale T, Tsang DS, Laperriere N, Kulkarni A, Ibrahim GM, Drake J, Dirks P, Taylor MD, Rutka JT, Laughlin S, Shroff M, Shago M, Hazrati LN, D’Arcy C, Ramaswamy V, Bartels U, Huang A, Bouffet E, Karajannis MA, Santi M, Ellison DW, Tabori U, Hawkins C (2020) Integrated molecular and clinical analysis of 1,000 pediatric low-grade gliomas. Cancer Cell 37:569-83.e5

Schüller U, Iglauer P, Dorostkar MM, Mawrin C, Herms J, Giese A, Glatzel M, Neumann JE (2021) Mutations within FGFR1 are associated with superior outcome in a series of 83 diffuse midline gliomas with H3F3A K27M mutations. Acta Neuropathol 141:323-325

Sievers P, Stichel D, Schrimpf D, Sahm F, Koelsche C, Reuss DE, Wefers AK, Reinhardt A, Huang K, Ebrahimi A, Hou Y, Pajtler KW, Pfister SM, Hasselblatt M, Stummer W, Schick U, Hartmann C, Hagel C, Staszewski O, Reifenberger G, Beschorner R, Coras R, Keyvani K, Kohlhof P, Diomedi-Camassei F, Herold-Mende
C, Giangaspero F, Rushing E, Giannini C, Korshunov A, Jones DTW, von Deimling A (2018) FGFR1:TACC1 fusion is a frequent event in molecularly defined extraventricular neurocytoma. Acta Neuropathol 136:293-302

Sievers P, Appay R, Schrimpf D, Stichel D, Reuss DE, Wefers AK, Reinhardt A, Coras R, Ruf VC, Schmid S, de Stricker K, Boldt HB, Kristensen BW, Petersen JK, Ulhøi BP, Gardberg M, Aronica E, Hasselblatt M, Brück W, Bielle F, Mokhtari K, Lhermitte B, Wick W, Herold-Mende C, Hänggi D, Brandner S, Giangaspero F, Capper D, Rushing E, Wesseling P, Pfister SM, Figarella-Branger D, von Deimling A, Sahm F, Jones DTW (2019) Rosette-forming glioneuronal tumors share a distinct DNA methylation profile and mutations in FGFR1, with recurrent co-mutation of PIK3CA and NF1. Acta Neuropathol 138:497-504

Sievers P, Schrimpf D, Stichel D, Reuss DE, Hasselblatt M, Hagel C, Staszewski O, Hench J, Frank S, Brandner S, Korshunov A, Wick W, Pfister SM, Reifenberger G, von Deimling A, Sahm F, Jones DTW (2020) Posterior fossa pilocytic astrocytomas with oligodendroglial features show frequent FGFR1 activation via fusion or mutation. Acta Neuropathol 139:403-406

Surrey LF, Jain P, Zhang B, Straka J, Zhao X, Harding BN, Resnick AC, Storm PB, Buccoliero AM, Genitori L, Li MM, Waanders AJ, Santi M (2019) Genomic analysis of dysembryoplastic neuroepithelial tumor spectrum reveals a diversity of molecular alterations dysregulating the MAPK and PI3K/mTOR pathways. J Neuropathol Exp Neurol 78:1100-1111

Touat M, Ileana E, Postel-Vinay S, Andre F, Soria JC (2015) Targeting FGFR Signaling in cancer. Clin Cancer Res 21:2684-2694

Voss MH, Hierro C, Heist RS, Cleary JM, Meric-Bernstam F, Tabernero J, Janku F, Gandhi L, Iafrate AJ, Borger DR, Ishii N, Hu Y, Kirpicheva Y, Nicolas-Metral V, Pokorska-Bocci A, Vaslin Chessex A, Zanna C, Flaherty KT, Baselga J (2019) A phase i, open-label, multicenter, dose-escalation study of the oral selective FGFR inhibitor Debio 1347 in patients with advanced solid tumors harboring FGFR gene alterations. Clin Cancer Res 25:2699-2707

Yang RR, Aibaidula A, Wang WW, Chan AK, Shi ZF, Zhang ZY, Chan DTM, Poon WS, Liu XZ, Li WC, Zhang RQ, Li YX, Chung NY, Chen H, Wu J, Zhou L, Li KK, Ng HK (2018) Pediatric low-grade gliomas can be molecularly stratified for risk. Acta Neuropathol 136:641-655

Zhang J, Wu G, Miller CP, Tatevossian RG, Dalton JD, Tang B, Orisme W, Punchihewa C, Parker M, Qaddoumi I, Boop FA, Lu C, Kandoth C, Ding L, Lee R, Huether R, Chen X, Hedlund E, Nagahawatte P, Rusch M, Boggs K, Cheng J, Becksfort J, Ma J, Song G, Li Y, Wei L, Wang J, Shurtleff S, Easton J, Zhao D, Fulton RS, Fulton LL, Dooling DJ, Vadodaria B, Mulder HL, Tang C, Ochoa K, Mullighan CG, Gajjar A, Kriwacki R, Sheer D, Gilbertson RJ, Mardis ER, Wilson RK, Downing JR, Baker SJ, Ellison DW (2013) Whole-genome sequencing identifies genetic alterations in pediatric low-grade gliomas. Nat Genet 45:602-612

Publisher's Note Springer Nature remains neutral with regard to jurisdictional claims in published maps and institutional affiliations. 